\title{
New Evidences: React Faster to Auditory and Tactile Spatial Targets of the Congenitally Blind
}

\author{
Ahmad M. Alghraibeh¹, Abdulaziz Majid Al-Skeiry² \\ ${ }^{1}$ College of Education, Department of Psychology, King Saud University, Riyadh, KSA \\ ${ }^{2}$ Undergraduate Student, College of Education, Department of Psychology, King Saud University, Riyadh, KSA \\ Email: aalghraibeh@KSU.EDU.SA
}

How to cite this paper: Alghraibeh, A.M and Al-Skeiry, A.M. (2019) New Evidences: React Faster to Auditory and Tactile Spatial Targets of the Congenitally Blind. Open Access Library Journal, 6: e5294. https://doi.org/10.4236/oalib.1105294

Received: February 25, 2019

Accepted: March 25, 2019

Published: March 28, 2019

Copyright $\odot 2019$ by author(s) and Open Access Library Inc.

This work is licensed under the Creative Commons Attribution International License (CC BY 4.0).

http://creativecommons.org/licenses/by/4.0/

\begin{abstract}
Congenital blindness is one of the rare human models to explore the role of experience-driven cross-modal compensation after early sensory deprivation. The auditory and tactile stimuli were now presented in sequence. Although both groups performed the task with similar accuracy, we observed that blind participants had shorter reaction times than sighted controls for the detection of spatial targets in both sensory modalities.
\end{abstract}

\section{Subject Areas}

Education

\section{Keywords}

React, Auditory, Tactile Spatial, Congenitally Blind

\section{Background}

This study aimed at exploring new evidences on sensational and visual reactions of blind people, that is, those who suffer loss of vision, where the project idea is to investigate the effectiveness of senses used by mental tools capable to examine the efficient senses capability among the research participants.

Studying people with vision losses is an excellent opportunity to find out how audio and sensory information process is formulated among blinds. Each day in the life of these individuals, they increasingly use the information obtained from their operating sensations, and this increased usage of these senses by those people supports the compensational behavior among blind people, and that blind people perform better on audio-touching Perceptual tasks, such as speech, recognizing tine periods, linguistic listening and recalling tasks [1]. Nu- 
merous events exist in daily life, which motivate the sensory system, and accumulated research body has emphasized that perception can be enhanced by the integration of information through multiple senses; [2] [3] conducted a study entitled spatial auditory attention which is modulated by tactile priming which showed that treatment by modularities affected perception in various nerve cells levels; and in another study, Collignon; Rerier, Bruyer, Tramdy \& Verart, [4]; Yin, Zeyl, Saab, Hu, Zhou, \& Chau, [5] entitled: Improved selective and divided spatial attention in Early Blind subject: which employed spatial attention model by using audio or tactile stimulation to explore behavioral and neural restructuring among early loss of vision; and the study revealed that the two groups were not different either in tactile sense in reaction time to the task.

There are additional evidences that blind participants have faster tactile and auditory reaction toward participants was shorter to spatial targets using sensual methods [6] [7].

Studying blind persons is an opportunity to find out how can experience be formed through audio treatment. Blind people rely more on audio information in their daily life, than normal vision people so as to identify persons and internalizing events or lingual process. An increasing number of studies have provided evidence suggesting that that the increasing use of auditory system outcomes support the compensation mechanisms among blinds, and that blind people perform better on audio perceptual tasks, such as speech, recognizing time period, linguistic listening and recalling tasks. This article concluded with evidences that reorganizing mulishness brain regions and reduced Modulators interactions on the behavioral level resulted from birth vision loss [8].

Hearing is the first sense on which bind people relay in getting information than other senses, as hearing enables the blind to get information through verbal communication and keeps the person in contact with social and physical phenomena in his environment, but as for communicating with physical environment, hearing efficiency diminishes and decreases to a significant extent, people may or may not speak [9].

In addition to that many objects do not make sounds, therefore the blind must rely on touching sense which helps him perceiving volumes and shapes [8].

Developing hearing perception in visual impaired persons helps in directing their movements and identifying things and voices resulting from environmental objects to help them identifying their locations and perceiving voices which protect the blind and provide him with safety and security also transportation coaches of the blind place a great importance during training on transportation skills, on hearing perception through movements across the environment [10].

So, tactile sense is the most important tool used by blind persons, because hands are a major source to communicate with external world, and this means that hand has a significant impact on blind individual social and economic life [11].

Touching sense develops through the first year of one's age, therefore toddlers discover things not only lips, in addition, warm and intimate communication 
provides stimulant sense, where this sense works on developing cognitive awareness during early childhood especially when discovering solid, soft, and tough things [10], so it is essential to provide children, especially blind ones, with learning experiences based on touching sense where it transfers information acquired by touch to the brain to be encoded and gives appropriate meaning and interpretation, but to develop touch sense, related mechanical skills should be developed, such as hands movements fingers positions, wrist elasticity, and hand lightness [12].

\subsection{Stimuli Responses and Resulting Reaction}

Reactions are defined as the fast response by the body for its exposure to a sudden stimulus such as putting hands on hot water or tearing, Bone marrow is responsible for this reaction, as it receives the stimulus in the suitable are where an appropriate response is given that moves through kinetics neural cell to the responding organism, and several studies proved that the disabled response to his surroundings differs according to senses through which the message entered, and speed of his response to the letter depends on the speed of the stimulus object, as well as reactions differs from one sense to another, but increasing senses participated in the response increase the efficiency of perception resulting in better learning [13].

Functional treatment showed that sensual integration in the man represents brain food jus as food represents muscles diet, for neural processes organize different feelings coming from the body through various sensed and through environment, followed by the appropriate response to those feeling which are Moto behavioral in form, meanwhile functional treatment showed also that sensual integration in the man is connecting between brain and behaviors made by the individual, when someone pushes us forward, our body automatically adjusts its position to avoid falling backwards, and when we see a potential threat, we try escaping it with our maximum energy. And all these reactions and responses are resulting of our sensual integration that sends signals to our brain to perform his role by sending suitable movement and behavior for each state depending on what the brain received of our various senses, and we can imagine the situation in which the visually impaired person exists as he loses one of his major senses, and how his conducts and behaviors will be, as well as his emphasis on other senses [14].

Parent and teachers work on providing the disabled child with experiences that help him develop and learn, and through senses development, the blind child learns compensational learning strategies that enable him in compensating what he has lost as a result of his disability. It should be emphasized that sensual compensation is not a gift as it is a sort of rewarding and continuous fort and training, so, any effectiveness or efficiency among visually disabled persons, in explaining received information, must be interpreted in light of attentions practice, adaptation, and increased usage of remaining senses [2]. 
Psychologists and sociologist, in explaining that, picture how a person perception of an event by combined equation: Existence of sensory system + connecting organisms + special centers in the brain, therefore any event acquired by the man or transferred to him from the external world through senses in the form of electrical current that connects this event to the brain as it is the major part in the central neural system, so, sensing organism receives the stimuli causing the sensation, and the neural (system hearing and tactile for example) sends message or signals to the brain in the form of information about the stimulus given that the speed of signal movements in the neural system in the mankind reaches about $(30.000) \mathrm{cm} /$ second, and the brain in light of past experiences, interprets these signals or information and understands it so the sensual perception occurs [15].

Studying individuals with blind or deaf special needs provides an opportunity to examine the perceptual and neural consequences of modality-specific sensory deprivation. For instance, blind subjects possess superior tactile discrimination [16] and auditory localization [17] [18].

A neural basis for these sensory enhancements is suggested by brain imaging studies showing activation of primary visual cortex in response to tactile or auditory stimuli of blind subjects [19] [20] [21] [22].

Blind subjects appear to have enhanced tactile abilities [23] and altered visual perception particularly for motion processing [24] [25]. Spatial attention paradigms with auditory and/or tactile stimulations were used to explore the putative neural and behavioural reorganization processes that occur after blindness. For example, in a study compared the selective and divided spatial attention abilities of Congenitally blind (CB) and sighted control (SC) participants, using sequences of auditory and tactile stimuli [26] [27].

Another study by Collignon et al., [4] observed that Congenitally blind participants showed better spatial attention abilities compared to sighted control during both the selective and divided spatial attention tasks when auditory and tactile stimuli were presented simultaneously.

To gain further insight into the multisensory attentional processes in the blind, the study is sought to explore selective and divided spatial attention abilities in CB and SC using a similar paradigm as in Collignon et al.'s study [4], except that this time auditory and tactile stimuli will be presented in sequence rather than simultaneously. When comparing attentional skills in CB and SC, it is particularly important for any experiment to exclude possible sensory confounds during the task because participants who are blind may possess sharpened sensitivity for the discrimination of basic features of auditory or tactile stimuli [17] [18] [28] [29] [30].

\subsection{Study Problem}

Visually impaired people effective adaptation with life requirements, and various complexities, requires learning multiple skills and strategies needed to confront 
these challenges, among these skills is training on senses development which includes vision hearing, touching and smelling.

Individuals with blind as categories of special education suffers from many problems, the most important problem is communication which affects their lives and their learning, and relations with others. Hearing and tactile senses are the ones on which blind people rely mostly in compensating a great part of deficits in experience caused by loosing vision or having poor sight, so it is considered one of most important senses after vision due to it is relationship with blind's communication and language. The need for developing skills of hearing and touching senses for the blind became important and necessary, therefore, hearing and tactile reactions in visually impaired persons will be investigated.

It is hoped that the results of this study will contribute in providing information for those in charge of blinds hearing and tactile skills development, it is also hoped that this study findings will benefit organizations working on rehabilitation of blind persons.

\subsection{Significance}

The significance of the study is represented by the subject which it addresses, and which is one of the important subjects in the area of taking care of visually impacted persons where this study aims at investigating or searching for additional evidences regarding hearing and tactile reaction of visually impaired persons.

It is also hoped that the results of this study with contribute in providing those in charge of blinds hearing and tactile skills development, it is also hoped that this study findings will benefit organization working on rehabilitation of blind persons.

\section{Method}

\subsection{Participants}

Ten participants who are blind with congenital peripheral deficits and ten sighted control (SC) participants were included in the study (see Table 1 for details). This experiment was approved by the Ethics Committee of the Deanship of Student Affairs at King Saud University. All participants were without any recorded history of neurological or psychiatric problems, reported normal hearing and tactile functions and did not use psychotropic medication at the time of testing.

\subsection{Materials and Stimuli}

Participants were individually tested in a soundproof room. Participant's head was stabilised in a straight ahead position by restraining the chin. Participants' hands lied on a table, with each hand $30 \mathrm{~cm}$ away from the body midline. Auditory stimuli were pure sinusoidal tones delivered through headphones. Tactile stimuli were trains of five short biphasic square wave pulses. Thusly, when 
Table 1. Characteristics of participants who are blind.

\begin{tabular}{ccccc}
\hline Participant & Age & Educational level & Sex & Onset of blindness \\
\hline 1 & 20 & Undergraduate & M & Congenital \\
2 & 21 & Undergraduate & M & Congenital \\
3 & 20 & Undergraduate & M & Congenital \\
4 & 19 & Undergraduate & M & Congenital \\
5 & 22 & Undergraduate & M & Congenital \\
6 & 22 & Undergraduate & M & Congenital \\
7 & 24 & Undergraduate & M & Congenital \\
8 & 22 & Undergraduate & M & Congenital \\
9 & 21 & Undergraduate & M & Congenital \\
10 & 23 & Undergraduate & M & Congenital \\
\hline
\end{tabular}

referring to tactile stimuli in the present manuscript, we refer to electrocutaneous stimulation. Vocal responses were used to determine reaction times.

\section{Results and Discussion}

SRT: Reaction times collected in the SRT tasks task (see Figure 1 and Figure 2) were analyzed by means of a 2 (group: blind, sighted) _ 2 (modality: auditory, tactile) factorial design ANOVA with repeated measures on the last factor.

In the SRT task, there was a significant effect showing that participants reacted more rapidly to tactile than to auditory stimuli. However, there is no significant main effect of the group factor. It is noteworthy that both groups reacted faster in the SRT to tactile stimuli than to auditory stimuli. Accordingly, the tactile stimuli could have hypothetically induced a stronger sensation than the auditory stimuli whereas left, right discriminations were more difficult for tactile targets than for auditory ones.

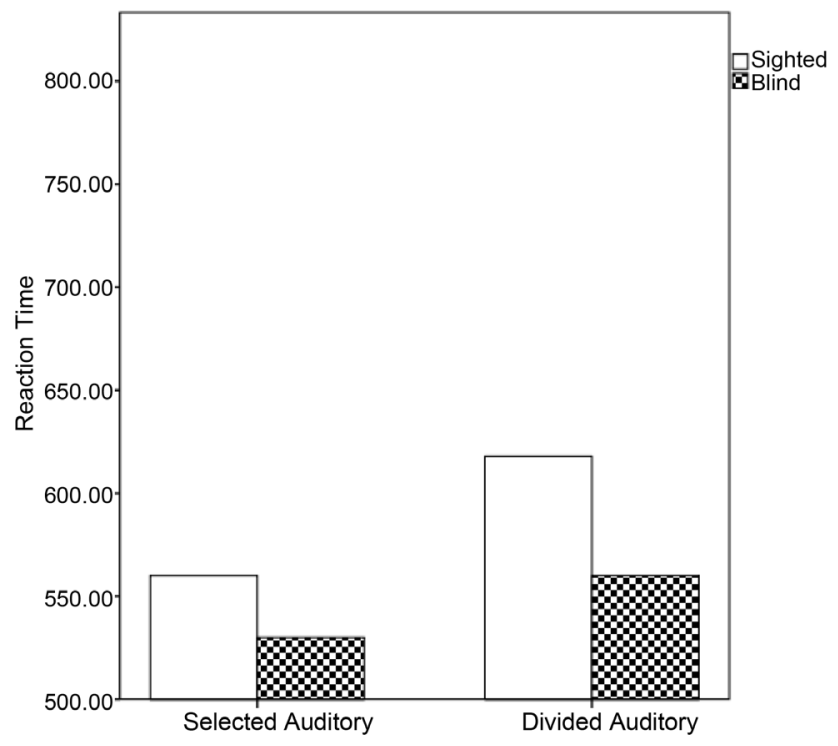

(a)

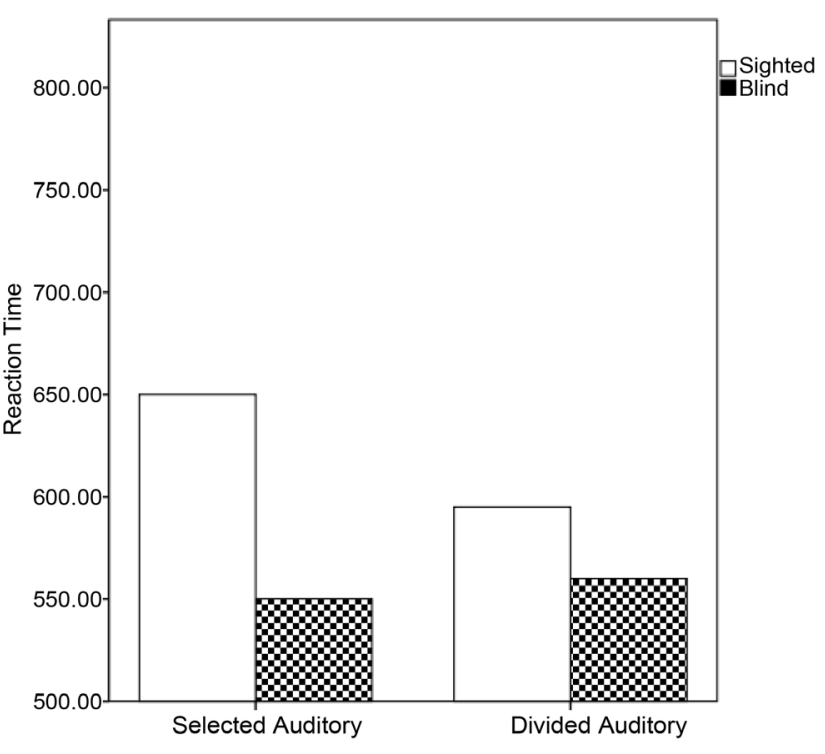

(b)

Figure 1. Reaction times in the spatial attention tasks. The latency of correct responses (means and standard errors of individual medians, in ms) is shown as a function of the group, the modality and the task. $\alpha=0.05$. 


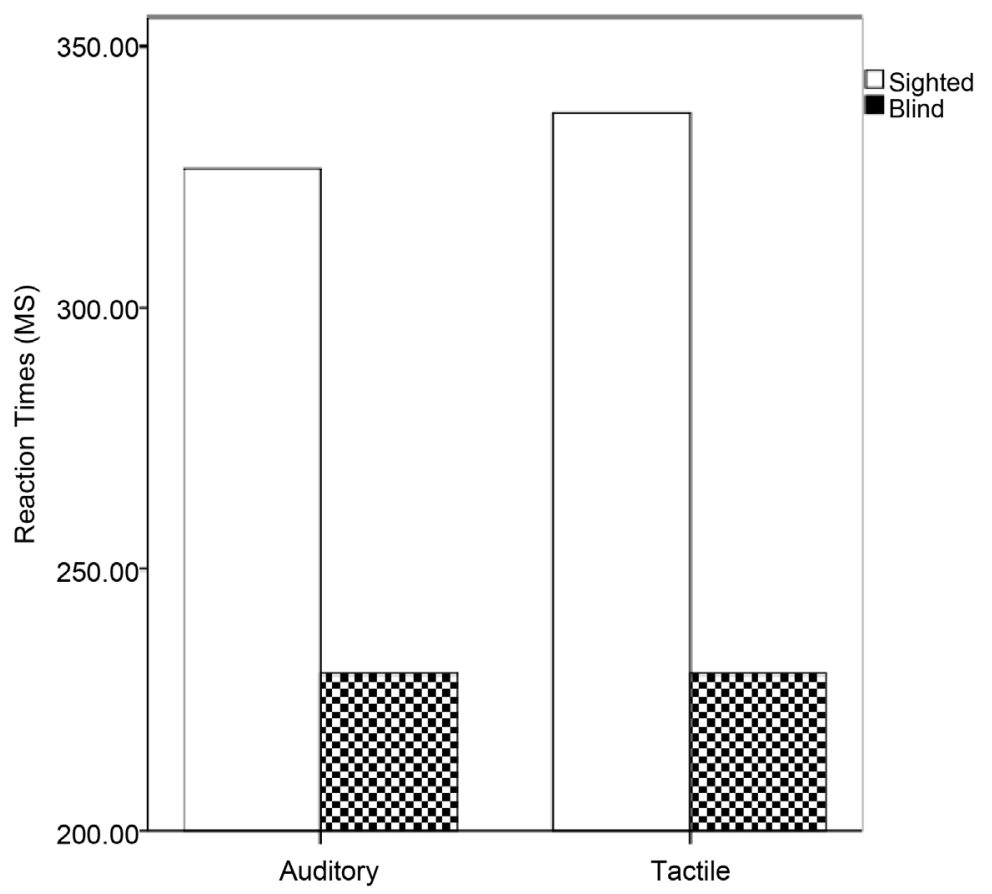

Figure 2. Reaction times in the simple reaction time task. The latency of responses (means and standard errors of individual medians, in $\mathrm{ms}$ ) is shown as a function of the group and the modality.

The present study provides compelling evidence for the presence of cross-modal compensation in $\mathrm{CB}$ by demonstrating that they reacted faster than SC to auditory and tactile spatial targets in selective and divided attention tasks. Individual adjustment of auditory and tactile stimuli insured independence of the reaction times from bottom-up sensory driven mechanisms such as differences in stimulus saliency between the two groups.

Moreover, the superiority of $\mathrm{CB}$ was the product neither of enhanced stimulus detection nor of response production because $\mathrm{CB}$ did not differ from SC in a SRT task using the same events. The results of the present study thusly strongly support the notion of a more efficient top-down attentional modulation of non-visual sensory events in participants who are blind [31].

In conclusion, the present results broaden our knowledge of the mechanisms underlying cross-modal compensation for visual loss, by demonstrating enhanced spatial attention in $\mathrm{CB}$.

\section{Compliance with Ethical Standards}

This study was conducted with approval from the responsible ethics committee (King Saud University, Ministry of Education) and in accordance with national law and the Helsinki Declaration of 1975 (in its current, revised form). Informed consent was obtained from all participants.

\section{Acknowledgements}

We extend our appreciation to the Deanship of Scientific Research, King Saud 
University for funding this work through the Undergraduate Student's Research Support Program (project No. USRSP-17-53).

\section{Conflicts of Interest}

The authors declare no conflicts of interest regarding the publication of this paper.

\section{References}

[1] Al-Rabiah, A. and Al-Zrayght, I. (2010) Types of Patter Bodily Behavior Practiced by Visually Impaired People and Its Relation to Their Gender and Severity of Their Disability in Saudi Arabia. Damascus University Journal, 26, 483-515.

[2] Menning, H., Ackermann, H., Hertrich, I. and Marthiak, K. (2005) Spatial Auditory Attention Is Modulated by Tactile Priming. Germany, Experimental Brain Research, 164, 41-47. https://doi.org/10.1007/s00221-004-2212-7

[3] Aylar, M.F., Jafarnezhadgero, A.A. and Esker, F.S. (2018) Sit-to-Stand Ground Reaction Force Characteristics in Blind and Sighted Female Children. Gait \& Posture, 62, 34-40. https://doi.org/10.1016/j.gaitpost.2018.03.004

[4] Collignon, O., Renier, L., Bruyer, R., Tranduy, D. and Veraart, C. (2006) Improved Selective and Divided Spatial Attention in Early Blind Subjects. Brain Research, 1075, 175-182. https://doi.org/10.1016/j.brainres.2005.12.079

[5] Yin, E., Zeyl, T., Saab, R., Hu, D., Zhou, Z. and Chau, T. (2016) An Auditory-Tactile Visual Saccade-Independent P300 Brain-Computer Interface. International Journal of Neural Systems, 26, Article ID: 1650001. https://doi.org/10.1142/S0129065716500015

[6] Collignon, O. and DeVolder, A. (2009) Further Evidence That Congenitally Blind Participants React Faster to Auditory and Tactile Spatial Targets. Canadian Journal of Experimental Psychology, 63, 287-293. https://doi.org/10.1037/a0015415

[7] Aylar, M.F., Jafarnezhadgero, A., Esker, F.S., Barber, R. and Robertson, D.G.E. (2017) The Effect of Time Restricted Visual Sensory Input on Asymmetry of Ground Reaction Force Components in Female Children. Journal of Bodywork and Movement Therapies, 22, 917-923. https://doi.org/10.1016/j.jbmt.2017.11.010

[8] Hotting, K. and Roder, B. (2009) Auditory and Auditory-Tactile Processing in Congenitally Blind Humans. Hearing Research, 258, 165-174.

https://doi.org/10.1016/j.heares.2009.07.012

[9] Gherri, E., Gooray, E. and Forster, B. (2016) Cue-Locked Lateralized Components in a Tactile Spatial Attention Task: Evidence for a Functional Dissociation between ADAN and LSN. Psychophysiology, 53, 507-517.

https://doi.org/10.1111/psyp.12596

[10] Cappagli, G., Cocchi, E. and Gori, M. (2017) Auditory and Proprioceptive Spatial Impairments in Blind Children and Adults. Developmental Science, 20, e12374. https://doi.org/10.1111/desc. 12374

[11] Hussein, A. (2003) Raising and Educating Blind People. Alam Al-Kotob for Publishing, Cairo.

[12] Biblalwi, K. and Abdelbaghi, E. (2005) Perceiving a Proposal for developing sensual skills among Visually Impaired Children. A Study Presented at Special Needs Education Meeting in Saudi Arabia.

[13] Bruns, P., Spence, C. and Röder, B. (2011) Tactile Recalibration of Auditory Spatial 
Representations. Experimental Brain Research. Experimentelle Hirnforschung. Expérimentation Cérébrale, 209, 333-344. https://doi.org/10.1007/s00221-011-2543-0

[14] Kathleen, B. and Eliassen, J. (1998) Modular Organization of Cognitive System Masked by Interhe Mispheric Integration. Science, 280, 902-906. https://doi.org/10.1126/science.280.5365.902

[15] Breus, T. (2006) Brains That Controls Mood.

[16] Blank, M. and Bridger, W. (1966) Conceptual Cross-Model Transfer in Deaf and Hearing Children. Child Development, 37, 29-38. https://doi.org/10.2307/1126426

[17] Lessard, N., Pare, M., Lepore, F. and Lassonde, M. (1998) Early-Blind Human Subjects Localize sound Sources Better than Sighted Subjects. Nature, 395, 278-280. https://doi.org/10.1038/26228

[18] Muchnik, C., Efrati, M., Nemeth, A., Malin, M. and Hildesheimer, M. (1991) Central Auditory Skills in Blind and Sighted Subjects. Scandinavian Audiology, 20, 19-23. https://doi.org/10.3109/01050399109070785

[19] Cohen, L., Celnik, P., Pascual-Leone, A., Corwell, B., Faiz, L., Dambrosia, J., Honda, M., Sadato, N., Gerloff, C. and Catala, M. (1997) Functional Relevance of Cross-Modal Plasticity in Blind Humans. Nature, 389, 180-183. https://doi.org/10.1038/38278

[20] Sadato, N., Pascual-Leone, A., Grafman, J., Ibanez, V., Deiber, M., Dold, G. and Hallett, M. (1996) Activation of the Primary Visual Cortex by Braille Reading in Blind Subjects. Nature, 380, 526-528. https://doi.org/10.1038/380526a0

[21] Kujala, T., Palva, M., Salonen, O., Alku, P., Huotilainen, M., Jarvinen, A. and Naatanen, R. (2005) The Role of Blind Humans' Visual Cortex in Auditory Change Detection. Neuroscience Letters, 379, 127-131.

https://doi.org/10.1016/j.neulet.2004.12.070

[22] Saville, C.W., Feige, B., Kluckert, C., Bender, S., Biscaldi, M., Berger, A., Klein, C., et al. (2015) Increased Reaction Time Variability in Attention-Deficit Hyperactivity Disorder as a Response-Related Phenomenon: Evidence from Single-Trial Event-Related Potentials. Journal of Child Psychology and Psychiatry, 56, 801-813. https://doi.org/10.1111/jcpp.12348

[23] Levanen, S. and Hamdorf, D. (2001) Feeling Vibrations: Enhanced Tactile Sensitivity in Congenitally Deaf Humans. Neuroscience Letters, 301, 75-77. https://doi.org/10.1016/S0304-3940(01)01597-X

[24] Bosworth, R. and Dobkins, K. (1999) Left Hemisphere Dominance for Motion Processing in Deaf Signers. Psychological Science, 10, 256-262. https://doi.org/10.1111/1467-9280.00146

[25] Bosworth, R. and Dobkins, K. (2002a) The Effects of Spatial Attention on Motion Processing in Deaf Signers, Hearing Signers, and Hearing Non-Signers. Brain and Cognition, 49, 152-169. https://doi.org/10.1006/brcg.2001.1497

[26] Kujala, T., Alho, K., Kekoni, J., Hamalainen, H., Reinikainen, K. and Salonen, O. (1995) Auditory and Somatosensory Event-Related Brain Potentials in Early Blind Humans. Experimental Brain Research, 104, 519-526. https://doi.org/10.1007/BF00231986

[27] Rutkowski, T.M. (2016) Robotic and Virtual Reality BCIs Using Spatial Tactile and Auditory Oddball Paradigms. Frontiers in Neurorobotics, 10, 20. https://doi.org/10.3389/fnbot.2016.00020

[28] Roder, B., Teder-Salejarvi, W., Sterr, A., Rosler, F., Hillyard, S. and Neville, H. 
(1999) Improved Auditory Spatial Tuning in Blind Humans. Nature, 400, 162-166. https://doi.org/10.1038/22106

[29] Van Boven, W., Hamilton, H., Kauffman, T., Keenan, P. and Pascual-Leone, A. (2000) Tactile Spatial Resolution in Blind Braille Readers. Neurology, 54, 2230-2236. https://doi.org/10.1212/WNL.54.12.2230

[30] Woods, D.L., Wyma, J.M., Yund, E.W., Herron, T.J. and Reed, B. (2015) Factors Influencing the Latency of Simple Reaction Time. Frontiers in Human Neuroscience, 9, 131. https://doi.org/10.3389/fnhum.2015.00131

[31] Olivier, C. and Anne, G. (2009) Further Evidence That Congenitally Blind Participants React Faster to Auditory and Tactile Spatial Targets. Canadian Journal of EXperimental Psychology, 63, 287-293. 